\title{
An Experience of Urban Transformation in Multan-Pakistani Punjab
}

\author{
Adalberto Del Bo, Daniele F. Bignami, Francesco Bruno, \\ Maria Vittoria Cardinale and Stefano Perego
}

\begin{abstract}
This publication concerns studies, programmes and designs for the project Sustainable Social Economic and Environmental Revitalization in the historic core of Multan City in Pakistani Punjab developed by several Politecnico di Milano Departments and Fondazione Politecnico di Milano, an institution that cooperates with Politecnico di Milano in the research fields of architecture, engineering and industrial design. The activities are part of the Debt Swap Agreement signed in 2006 between the governments of Italy and Pakistan for development in the social sectors. Besides the extraordinarily valuable architecture of the Walled City of Multan and its dense and hard-working population, there is a physical and environmental condition that is extremely problematic and that may threaten the continuity of life in the historic part of a city, well known for being among the world's most ancient settlements. The social and cultural interest and the academic challenge of a new opportunity to deal with great traditions pushed the researchers to face the urgency and delicacy of a very complex theme. After the analysis, the surveys and the proposals, the Politecnico group completed the first operational phase reorganizing one of the main City Gate Place, building a new open pavilion and restoring a huge public building and the Gate. The last activity, planned and not yet implemented, refers to the Sarafa Bazaar Project, an integrated system for the urban arrangement through infrastructures systems as sewerage, public lighting and shading, new paving and conservation of historic building's façades.
\end{abstract}

\footnotetext{
A. Del Bo $(\varangle)$

Architecture, Built Environment and Construction Engineering-ABC Department, Politecnico di Milano, Milan, Italy

e-mail: adalberto.delbo@polimi.it

D. F. Bignami

Project Development Department, Fondazione Politecnico di Milano, Milan, Italy

F. Bruno

Milan, Italy

M. V. Cardinale $\cdot$ S. Perego

Milan, Italy

(C) The Author(s) 2020

S. Della Torre et al. (eds.), Regeneration of the Built Environment

from a Circular Economy Perspective, Research for Development,

https://doi.org/10.1007/978-3-030-33256-3_18
} 
Keywords City revitalization $\cdot$ Architecture $\cdot$ Conservation $\cdot$ Cross-cultural cooperation $\cdot$ Walled city

\section{Introduction}

The project "Sustainable, Social, Economic and Environmental Revitalization in the Historic Core of Multan City" is aimed at promoting socio-economic improvement and protection of historical and environmental heritage in the ancient Walled City of Multan in Pakistan.

The project, developed by Fondazione Politecnico di Milano, in cooperation with several departments of the Politecnico di Milano ${ }^{1}$ and in collaboration of few other research institutions ${ }^{2}$ is funded through the debt swap agreement between the Italian Government and the government of the Islamic Republic of Pakistan (PIDSA) and is supported by the Italian Embassy of Islamabad, Ministry of Foreign Affairs and International Cooperation of Italy, Italian Development Cooperation, and Pakistan Ministry of Finance, through its Economical Affair Division, and routed by the Ministry of Housing \& Works, during first phase, and by Local Government \& Community Development Department-Government of Punjab (LG \& CD), for the implementation of the second phase of the project.

Multan is one of the oldest cities in the Asian subcontinent, rich in history and culture, dating back at list 2000 years, but probably founded near 5000 BC and part of Indus Valley Civilization period (Cuneo 1986; Nabi 1983; Page 2008; Raza 1988; Sen 1988). It is located in the Southern Punjab Province in centre of Pakistan. The city is situated at the intersection of major roads linking the North and South of

\footnotetext{
${ }^{1}$ Polimi Departments: ABC (Architecture, built environment and construction engineering); ex BEST (Built environment science \& technology); DASTU (Architecture and urban studies); ex DIAP (Architecture and planning); DICA (Environmental and Civil Engineering); ex DPA (Architectural Design); INDACO (Industrial design arts and communication).

Polimi Workgroup: Christian Amigoni, Francesco Augelli, Daniele Beacco, Irene Bengo, Eleonora Bersani, Daniele F. Bignami, Daniele Bocchiola, Matteo Bogana, Paolo Bonasoni, Maurizio Boriani, Francesco Bruno, Barbara Calvi, Samuele Camolese, Gabriele Candiani, Maria Vittoria Cardinale, Nelly Cattaneo, Daniele Cerizza, Emanuela Colombo, Gabriele Confortola, Alessandro Conti, Giovanni Maria Conti, Paolo Cristofanelli, Giorgio Dalla Via, Enrico De Angelis, Adalberto Del Bo, Elena Dell'Oro, Claudio Di Benedetto, Vincenzo Donato, Dario Guerini Matteo Fiori, Lidia Fiorini, Maria Romana Francolino, Federico Frassy, Rossana Gabaglio, Giuseppe Galloni, Andrea Garzulino, Eugenio Gatti, Mariacristina Giambruno, Marco Gianinetto, Franco Guzzetti, Marco Introini, Ermes Invernizzi, Monica Lancini, Luca Listo, Michele Locatelli, Lorenzo Maffioli, Pieralberto Maianti, Andrea Mainini, Umair Malik, Carlo Manfredi, Andrea Marchesi, Roberta Mastropirro, Maria Teresa Melis,, Rasha Mozil, Vassilis Mpampatsikos, Giorgio Pansa, Riccardo Paolini, Stefano Perego, Davide Pini, Sonia Pistidda, Tiziana Poli, Renato Pugno, Letizia Ronchi, Renzo Rosso, Francesco Rota Nodari, Marco Rusmini, Andrea Soncini, Matteo Tasinato, Alessandra Terenzi, Grazia Tucci, Giorgio Valè, Paolo Vercesi, Gian Pietro Verza, Elisa Vuillermoz, Anna Sara Zanolla.

Scientific Director—Adalberto Del Bo; Project Manager—Daniele F. Bignami; Project Director phase I—Juan Xabier Monjas; Project Director phase II-Francesco Bruno.

${ }^{2} \mathrm{Ev}-\mathrm{K} 2-\mathrm{CNR}$ Committee and the University of Florence.
} 
the country (to Lahore and Karachi) and the routes going from East to West. Its geographical position makes Multan a crucial and strategic site in the country (Dutt 2004). As a consequence of the recent process of urbanization, Multan is now the core of a big hinterland of medium towns, large villages and small clusters of shacks.

Starting from this role, the need of crucial interventions to protect the "soul" of Multan was clearly highlighted by Pakistani authorities. Consequently, an urgent action of architectural heritage preservation of the Old Town has been evaluated as necessary, together with the commencement of a cultural and social development process within the Walled City, characterized by high population density, significant problems about energy, water and sanitation and many different commercial activities.

On the basis of available resources (Abu l'Fazl 1596) and of preliminary investigations, the project has been conceived aiming at developing a pilot model in conservation and revitalization of the oldest part of Multan, focused on specific areas and monuments of the Walled City, significant from the historical and symbolic point of view (Dani 2008; Rehman 1997; Hoagh 1978; Marshall 1937; Burckhardt 1985), and able to act as a guide intervention to be transferred in other areas of the Old Town. The main action of the project concerns the conservation of few selected historical buildings and the renewal of a part of the ancient historical centre.

The phase II of "Sustainable, Social, Economic and Environmental Revitalization in the Historic Core of Multan City" has been preceded by a careful and thorough series of studies, including investigations carried out accordingly to the theoretical and practical expertise of Politecnico di Milano, and the tools and the methods developed in its research tradition (Rossi 1966).

In a second step, the studies focused on a specific Walled City pilot area and on individual building characteristics through a specific survey carried out with the active collaboration of students from the Bahauddin Zakariya University of Multan.

With the collaboration of experts in different disciplines all the results, gathered in several publications ${ }^{3}$ and delivered by Fondazione Politecnico di Milano to Project Management Unit of the Walled City of Multan, were the fundamentals for the implementing phase of the conservation and the design renovation works within.

Regarding the organisational structure of the project, it is necessary to refer to some general provisions that allowed the planning, structuring and implementing of the different objectives and components. A Project Implementation Committee at the local level headed by the Commissioner-Multan Division-in collaboration with Fondazione Politecnico di Milano ensured that the project could be developed and implemented according to the directives of the Steering Committee.

The project was designed to be managed through a specially created Project Management Unit (PMU) working under LG \& CD, with the supervision of a high-level Steering Committee at Provincial level. The PMU closely coordinated the preparatory activities with the different involved line agencies (WASA, MEPCO, SNGPL,

\footnotetext{
${ }^{3}$ Cfr. Del Bo and Bignami (2014), Del Bo and Introini (2013), Augelli et al. (2015).
} 
$\mathrm{PTCL}^{4}$ ). On this regard, the PMU created two structures (Infrastructure Design and Management Group and Project Design and Management Team), which worked independently or jointly depending on the task.

The principal partnership under the project is with Fondazione Politecnico di Milano which provided and still provides the competence and the facilities to develop and coordinate the entire project tasks: guidelines for working drawings, outline plans, consultancy services and supervision aimed at the implementation of the entire activities.

\section{The Components of the Project}

The Multan Walled City, with an approximated area of $1.2 \mathrm{~km}^{2}$ and a population of around 127,000, was once the place where all the local arts were born and developed. The traditional arts are still alive in the area particularly in the form of jewellery, blue pottery and embroidery. There are approximately 3500 shops in Hussain Aghai Bazaar, Chowk Bazaar, Haram Bazaar and Sarafa Bazaar; about 1500 shops are pertaining to jewellery and manufacturing facilities and 1000 shops to textile sector. The approximate population associated with this business is almost 15,000 people; most of these people are employed on the shops and are within the poverty line. Therefore, the overall objective of the project was to initiate a sustainable process of social and economic revitalization and to upgrade the physical and environmental quality, through the improvement of livelihoods and living conditions of the residents.

For this reason, and for their characteristic and location inside the Walled City, the choice of the two main project areas-Haram Gate Place and Sarafa Bazaar-has been considered strategic for developing the pilot project as an example of possible future renovation inside the Walled City.

In addition, the selected precincts could enhance a more general touristy promotion by the improvement and conservation of the sites where the revitalized public space could be appreciated by the visitors. All this related to the conservation of the Haram Gate as an architectural heritage to be preserved for the collective citizen memory. Moreover, proposing a technical reorganization of the facilities aimed at the enhancement and the improvement of public space: i.e. enhancement of sewer system, electricity reorganization and urban shading.

A brief description could help in understanding the entity and the complexity of the second phase of the project, including the following components: Haram Gate conservation and Haram Gate Place regeneration, Musafir Khana building restoration, portion of Sarafa Bazaar regeneration and several capacity building activities.

\footnotetext{
${ }^{4}$ Water and Sanitation Agency, Multan Electric Power Company, Sui Northern Gas Pipelines Limited and Pakistan Telecommunication Company Limited.
} 
In relation to these preliminary objectives, the physical working phase has quite been totally completed, except for the Sarafa Bazaar, for which the working documents have been finalized and the construction site is expected to be opened in few months.

The first project component is the Haram Gate area, one of the most important gateways to the Walled City. Today the precinct is a place of traffic and a starting point of an important tourist route that leads to inner part of the Walled City. The west side of the place, towards Alang Road, has been subject to recent demolitions of a part of the urban texture built on the original site of the ancient city walls. Together with the Gate conservation project, there was the need to act with a plan for the entire reorganization of the place. The Haram Gate Place project, in fact, is strictly connected with the Haram Gate conservation project, with the aim to create a real urban place, in opposition to the current traffic and parking place, as a communitarian site located at the entrance of the Walled City. For this purpose, the project shaped a new sequence of spaces around the Haram Gate: the entire area-between the Circular road and the Gate- has been paved with bricks, a new lighting system has been settled, trees have been planted along the side of the place facing Circular Road, and a new pavilion has been built, on the site of several ruined buildings, to create a sort elevated terrace, covered by a steel and wooden structure, where the inhabitants as well as the tourist, could enjoy a protected space.

The small pavilion refers to the typical elements of the architectural tradition of the great royal gardens: the diwan was in fact a resting place in the shade set within a composition of geometries and perspectives.

Compared to the first phase of the project, the pavilion underwent some substantial changes regarding its shape and the materials. In fact, related to the architectural characteristics of the building and the role it plays in the reorganization of the square, its proportions have been revised. It has in fact opted for a plan based on a 3:5 ratio clearly expressed thanks to the adopted structural step. The same ratio was maintained between the short side and the height of the building. The design of the flooring and the choice of materials remained almost unchanged compared to the first proposals. The paving of the square is continuous and made with a brick already used for the inner street inside the Walled City. The edge surface of the pavilion stylobate is made within local white granite with pinkish veins about $30 \mathrm{~cm}$ wide.

The development of the project has also led to the revision of some initial choices due to more simplicity of construction and availability of materials. For this reason, the roof of the building, initially designed with triangular section beams that needs a very complex manufacturing, has been redesigned with standardized elements in iron and for the secondary structure in wood. The whole roof was covered in wood with staves about $15 \mathrm{~cm}$ wide and painted red as well as the elements of the building. The choice to simplify the design of the elements that make up the pavilion also guaranteed the involvement of local workers from the Multan district.

Related to the relationship with the surrounding space and orientation, the roof has three overhangs on the east, south and west sides, while the north side, towards the toilets, is devoid of them. To increase the shading, a row of trees placed to the 
south, at the level of the circular road, completes the design of the limit of Haram Gate Place.

The discovery of an ancient well to the east of the pavilion during the excavation activities required a revision of the design of the big steps that connecting the street level to the podium. Thanks to an accurate survey of the discovered well about its dimensions and position, the design of the big steps - made by the same granite used for the pavilion stylobate-was redefined with a centre in the ancient well that today is visible thanks to a glass covering.

The pavilion is a covered construction provided by seats for the waiting and rendezvous. This kind of traditional building has been placed along north-south direction, becoming the support of amorphous photovoltaic surfaces, able to produce enough electricity to light its illumination system during the night. To complete the empty area on the north side, created by the demolitions, a services building, is located in front of the new pavilion, provided of public washroom.

For achieving the complete results and make the Gate free from every kind of encroachment-for instance the "crowd" of overhead cables running along the place-preliminary to its conservation works, it was necessary to improve and reorganize all the infrastructure system in the vicinity; i.e. the telecommunication and the electric power distribution infrastructure, the water supply system, the natural gas distribution, the sewage disposal and the storm water drainage systems (Wang et al. 2011), all of them replaced with underground lines.

The Haram Gate project achieved an exemplary conservation intervention in a field which is strategic for a country rich of monuments. The conservation and the strengthening techniques answered to the problems of decay and instability that were causing the serious state of deterioration of the building. The theoretical approaches and the technical solutions provided, in line with the most advanced methods of restoration in the international scenario, allowed to reach an expected result in term of intervention quality.

In accordance to the same considerations, it should be read the second component of the project which has been fulfilled with the completion of the Musafir Khana renovation. The building is an important historical legacy of the inner city of Multan and it is located in a strategic area characterized by several Holy Sites. The symbolic, historic and cultural importance of the Musa Pak complex makes it one of the most significant and representative within the historical core of Multan.

The third component taken into consideration by the Multan Walled City initiative is the Sarafa Bazaar project, the only one among those planned not yet completed, for which, however, all the materials necessary for the working phase have been totally finalized. The relevant portion of the Sarafa Bazaar project extends from Musafir Khana to the North. The bazaar, in accordance with its commercial nature, presents at the ground floor spaces used for shops and on the upper floors are located laboratory and dwellings.

The aim of the project is to bring order to the bazaar through a general arrangement able to represent both the local tradition and the necessary innovation in infrastructures, tourism improvement and energy saving. 
Sarafa Bazaar Project provides an integrated system for the urban arrangement through infrastructures; public lighting; shading system; new paving; facades improvements and conservation of historic building's façades.

Sarafa Bazaar Project foresees the restoration of the façades. This kind of process is focused on urban and social problems with the purpose of a new general urban quality. The regeneration of a part of Sarafa Bazaar with a wide re-design project of the historic and recent building's façades wants to face problems as organization of public spaces, accessibility to the Old Town, insufficient lighting, traffic, security, and so on.

The general goal is to improve the life quality of the inhabitants, encouraging the tourism and make the city more attractive for the economic activities. So, the facades and open spaces rehabilitation and the facilities services improvement could have a positive effect on the re-appropriation of the spaces from the inhabitants that could inspire further actions on the interior spaces and the contiguous areas with a general improvement of the life quality. A regenerated space could become more attractive for tourism, producing a general improvement of the local micro economy. The urban rehabilitation requires, even more than the restoration of single monument, an overall program to build a general agreement of ideas and a shared involvement of the resident population.

The fourth and final component provided by the project is to develop a capacity building programme, based on a University networking. Therefore, the execution of the project offered a double opportunity: on the one hand, the collaboration of Italian and Pakistani personnel in the execution of the works, on the other hand, the opportunity to develop new skills in Pakistan in the architectural field. The proposed topics are both related to practical and theoretical aspect concerning the project and related to the architectural and urban planning theories.

The practical modalities and the intervention techniques with which it was possible to achieve the project outcome are in fact closely linked to specific knowledge on the restoration procedures as well as in the survey filed and data collection. Those disciplines are, in cases like this, the tools themselves for the development of the architectural project and its practice, especially in complex areas such as the Islamic city.

In conclusion, as described, the project is an important example of cross-cultural cooperation and collaboration project in the field of urban regeneration and transformation, showing how academic competencies, coordinated by a specialized structure of management of research and knowledge transfer projects can meet ambitious objectives and the challenge of achieving real improvements of delicate, but precious urban context (Figs. 1, 2, 3 and 4). 


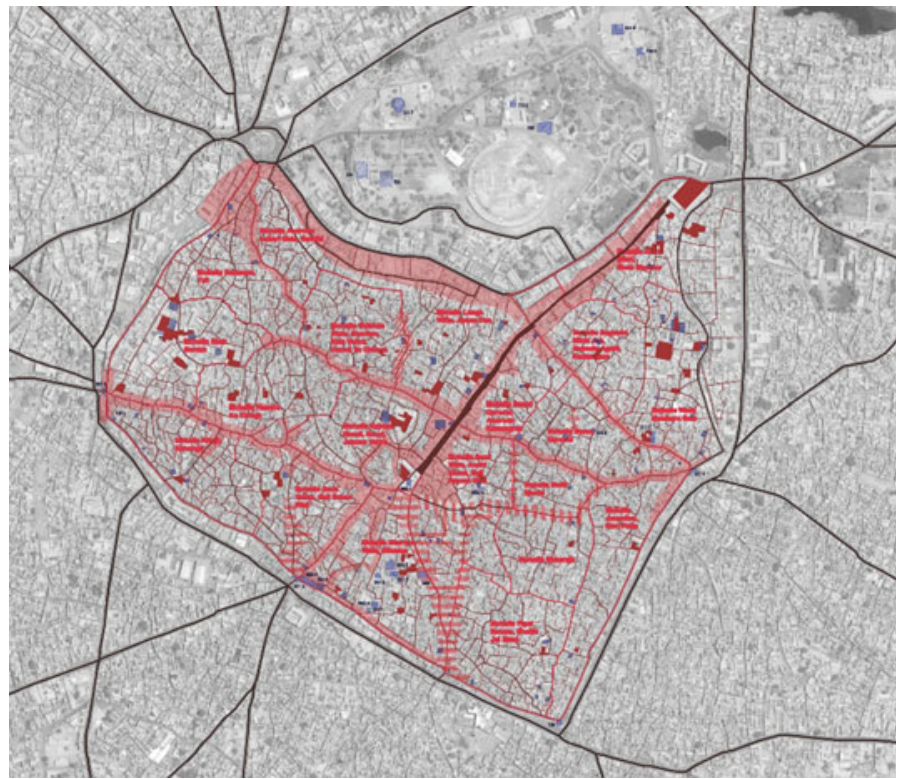

Fig. 1 Walled city of Multan and the Mohalla structure (in red)

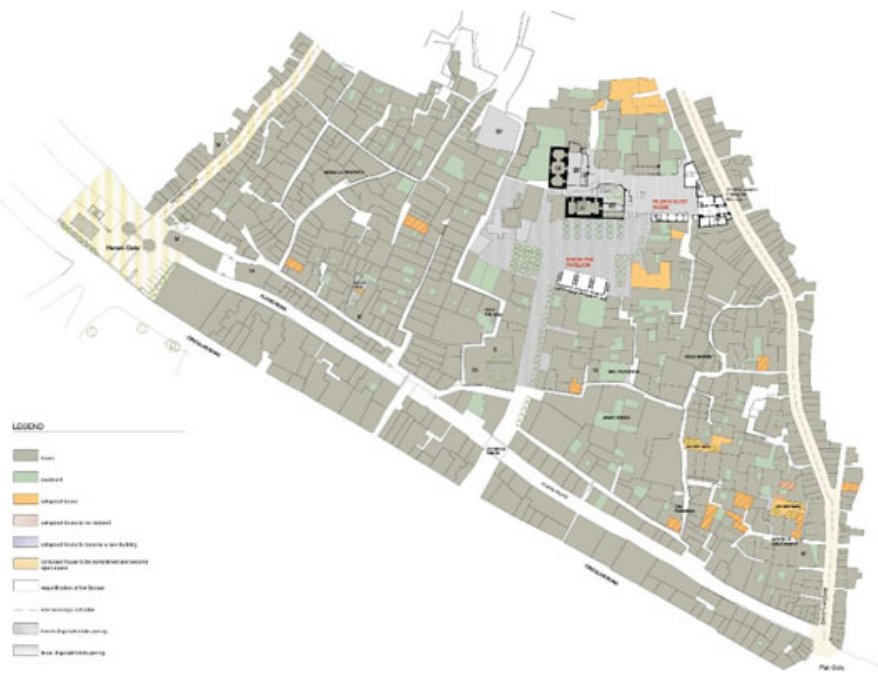

Fig. 2 Multan. Pilot area Masterplan 


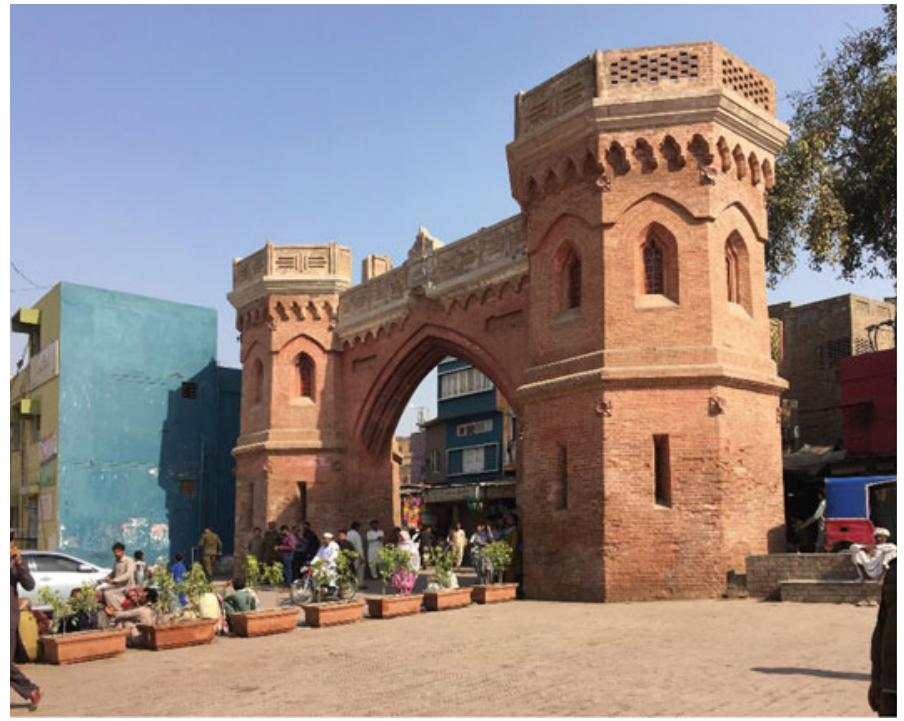

Fig. 3 Multan. Haram Gate after conservation work

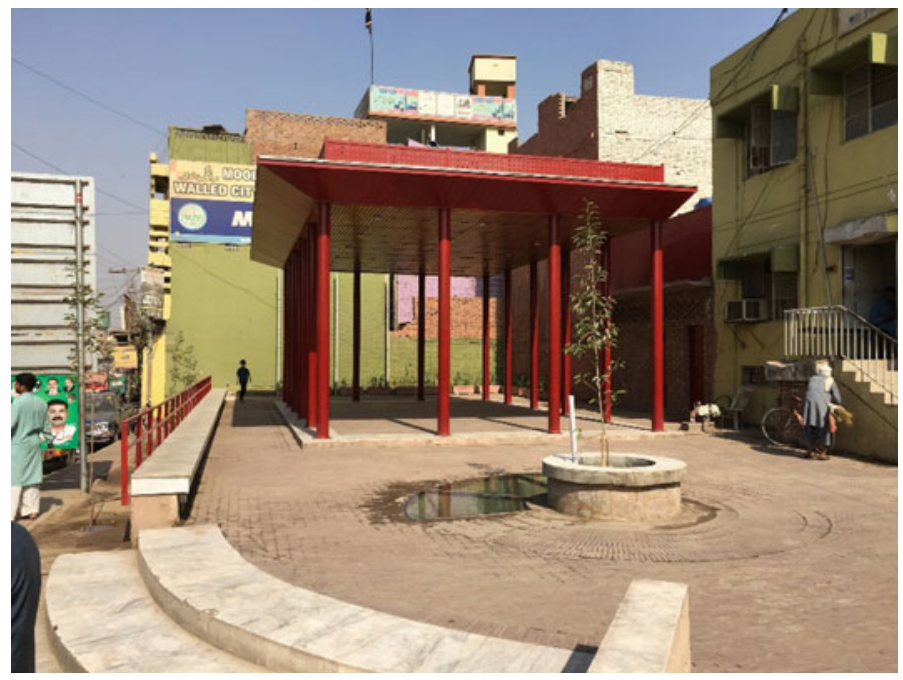

Fig. 4 Multan. Haram Gate Place and the New Pavillion 


\section{References}

Abu l'Fazl. (1596). Akbarnama (by H. Beveridge, The Asiatic Society, 2000).

Augelli, F., Giambruno, M. C., Mastropirro, R., \& Pistidda, S. (2015). The walled city of Multan. Guidelines for maintenance, conservation and reuse work. Firenze: Altralinea. ISBN 978-8898743-50-6.

Burckhardt, T. (1985). L'art de l'Islam, Langage et signification. Arles: ACTES SUD.

Cuneo, P. (1986). Storia dell'urbanistica-Il mondo islamico. Bari: Laterza.

Dani, A. H. (2008). History of Pakistan. Lahore: Sang-E-Meel Publications.

Del Bo, A., \& Bignami, D. F. (Eds.) (2014) Sustainable social, economic and environmental revitalization in Multan City. Cham, Heidelberg, New York, Dordrecht, London: Springer International Publishing AG. ISBN 978-3-319-02116-4.

Del Bo, A., \& Introini, M. (2013) Multan, Pakistan. La città murata. Milano: Silvana Editoriale. EAN: 9788836625628.

Dutt, R. C. (2004). The civilisation of India. New Delhi, Chennai: Asian Educational Services.

Hoagh, J. D. (1978). Architettura islamica. Milano: Electa Editrice.

Marshall, J. (1937). The monuments of Muslim India. In Cambridge history of India (Vol. 3). Cambridge, Dry.

Nabi, K. A. (1983). Multan history and architecture. Islamabad: Institute of Islamic History, Culture \& Civilization-Islamic University.

Page, J. B. (2008). Indian Islamic architecture (G. Michel, Ed.). Leiden, Boston: Brill.

Raza, M. (1988). Hanif, Multan past \& present. Islamabad: Colorpix

Rehman, A. (1997). Historic towns of Punjab. Ancient and medieval period. Rawalpindi, Lahore, Karachi: Ferozons (PVT) Ltd.

Rossi, A. (1966). The architecture of the city. Padova: Marsilio Editore.

Sen, S. N. (1988). Ancient Indian history and civilization. New Delhi: New Age International.

Wang, S.-Y., Davies, R. E., Huang, W. R., \& Gillies, R. R. (2011). Pakistan's two-stage monsoon and links with the recent climate change. Journal of Geophysical Research, 116(D16), 27. https:// doi.org/10.1029/2011JD015760.

Open Access This chapter is licensed under the terms of the Creative Commons Attribution 4.0 International License (http://creativecommons.org/licenses/by/4.0/), which permits use, sharing, adaptation, distribution and reproduction in any medium or format, as long as you give appropriate credit to the original author(s) and the source, provide a link to the Creative Commons license and indicate if changes were made.

The images or other third party material in this chapter are included in the chapter's Creative Commons license, unless indicated otherwise in a credit line to the material. If material is not included in the chapter's Creative Commons license and your intended use is not permitted by statutory regulation or exceeds the permitted use, you will need to obtain permission directly from the copyright holder. 